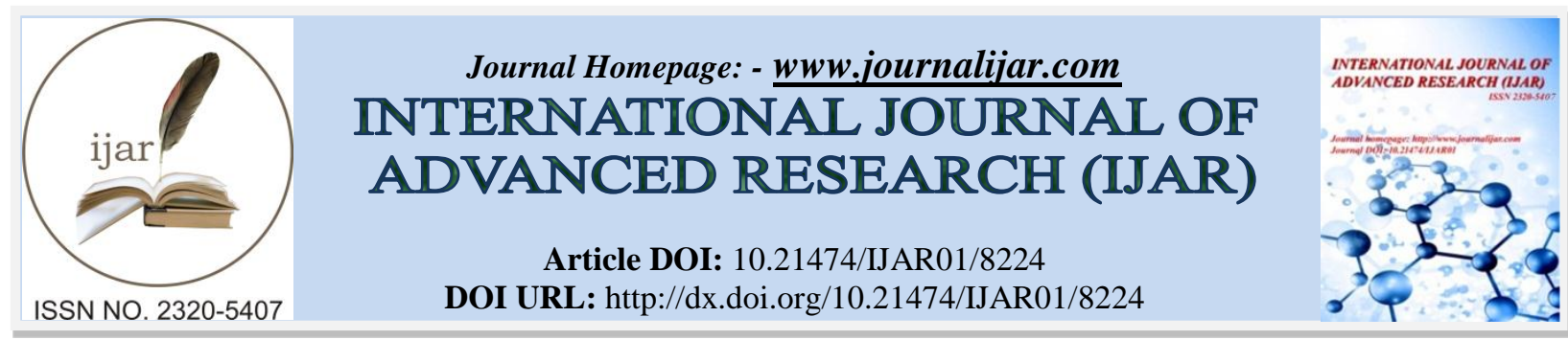

RESEARCH ARTICLE

\title{
THE EFFECT OF LEARNING MODEL "PLAN DO REVIEW" ON SCIENCE CAPABILITY OF CHILDREN IN KINDERGARTEN.
}

\author{
Herman and Rusmayadi. \\ Early Childhood Education Teacher Education Program, Faculty of Educational Science, Universitas Negeri \\ Makassar.
}

\section{Manuscript Info}

Manuscript History

Received: 18 October 2018

Final Accepted: 20 November 2018

Published: December 2018

Keywords:

Plan Do Review, Learning Model,

Science Capability.

\section{Abstract}

The purpose of this study was to determine the effect of the learning model "plan do review" of children's science capability. The type of research was Quasi Experiments. The research design used was nonequivalent control group. The sample of this study amounted 20 children consisting of 10 experimental groups and 10 control groups. Data collection techniques used were observation, tests and documentation. The data analysis technique used was the descriptive and inferential statistical analysis test with the $t$ test. The value of a child's science capability before being given treatment had an average of 16.00 which was lower than the average value of a child's scientific ability after being given a treatment of 18.00 . The results showed that there were differences in the value of children's scientific abilities before and after the plan do review learning model.

Copy Right, IJAR, 2018,. All rights reserved.

\section{Introduction:-}

Child education experts view early age as a golden age that only comes once and cannot be repeated. Early childhood is in the golden age throughout the age range of human development. At that time the child is in a sensitive period where at this time the child is specifically easy to receive various simulations of the environment. Kindergarten is one of the preschool education patterns in the formal education pathway. Preschool education is education to help the growth, development, genius and spirit of children outside the family environment before entering primary education.

The aim of the kindergarten learning program is to help lay the foundation for the development of attitudes, knowledge, skills and creativity that are needed by students in adjusting to the environment for growth and subsequent development. Growth and development achieved is the potential actualization of all aspects of child development optimally at each stage of its development. The level of developmental achievement describes the growth and development expected by children in a certain period of time. The level of achievement of child development includes aspects of understanding religious and moral values, physical-motoric, cognitive, language, and social-emotional. All aspects of this development are very important to be developed and are expected to be able to develop in a balanced manner between aspects of one another. This shows the importance of developing the potential of children, one of which is through the development of learning models that determine the success of children in the future.

\section{Corresponding Author:-Herman.}

Address:-Early Childhood Education Teacher Education Program, Faculty of Educational Science Universitas Negeri Makassar. 
(Jaipaul and James, 2011) states that the Plan Do Review learning model recognizes children as active learners, who learn the best way through the activities they plan, carry out and reflect on themselves. Adults use complex language when observing, helping, and expanding children's work if necessary. Adults regulate areas of interest and learning environments, maintain a daily routine that allows children to plan, do and reflect on their own activities, and join in children's activities, engage in conversations that sustain and expand children's plans and help them reflect many things. Adults encourage children to make decisions, solve problems, or engage in curriculum activities that contribute to their learning about those based on key development indicators that cover all intellectual, social, and physical development fields.

The Plan Do Review learning model gives children the freedom to actively learn and give freedom and children are involved directly in the learning process and provide experience with the people around them so that the learning environment must be able to help children grow cognitive abilities. In addition, the plan do review learning model also invites children to empathize, communicate, cooperate, and understand others.

(Morrison, 2012) explains that there are five main elements in implementing the Plan Do Review learning model, namely:

\section{Class Arrangement}

Classrooms are designed to suit the interests of children, where each interest has its own area. Each area is given a simple name that represents a picture of the area of interest to the child.

\section{Active Learning}

Children are directly involved in learning, experience in direct contact with people, objects, ideas and events. Active learning experiences will help children build their knowledge, such as: learning concepts, forming ideas, creating their own symbols and abstractions and teachers as facilitators.

\section{Content of learning}

The content of learning used is material that is in line with the development of children for children based on the main indicators of child development.

\section{Assessment}

Assessment is a key practitioner, this allows them to understand the level of mental development of the child, identify expressed interests, observe the key experiences that involve each child. Teachers in the Plan Do Review class record children's behavior, experience, and interests. They use their notes to assess developments and plan future activities to support children's growth and development. This assessment process requires group planning, daily observation records, a collection of recorded records each semester. These records are also used as parental information to help better understand child development.

\section{Daily schedule / daily routine.}

There are five processes according to (Morrison, 2012:109) that support daily schedules/daily routines supporting active learning. Among them:

1. Planning Time (Plan)

2. Main experience

3. Working Time (Do)

4. Cleaning up time

5. Devotional / Study Time (Review)

In this study, the researcher focused on three aspects of daily routines, the Plan Do Review Model, namely Plan, Do, and Review

\section{Plan (Time of Planning)}

Time planning gives children consistent and structured opportunities to express ideas to adults (teachers), and see them as individuals who can act on decisions. The teacher talks with the child about the plan they made before the child carried it out. This helps children clarify their ideas and think about how to proceed. Talking with children about their plans provides an opportunity for teachers to encourage and respond to each child's ideas, suggest ways 
to strengthen plans to succeed, and understand and measure the level of development and thinking style of each child.

\section{Do (Working Time)}

This part of the working time series is usually the longest period of time in the daily routine. The teacher's role during work time is to observe children to see how they gather information, interact with colleagues, and solve problems. If needed, the teacher enters child activities to encourage, expand, and design problem solving situations.

\section{Review (Time to Remember)}

When recalling, is the final stage of the Plan Do Review series is the time when the child tells the experience of work time in various ways that are appropriate to the developmental stages of each child. They can remember the name of the friend they involved in their plan, draw a picture of the building they arranged with blocks, or describe the problem they encountered. This study allows children to reflect on what has been done and how to do it. This stage is the closing for planning and work time activities. In this study, the steps or steps taken in implementing the Plan Do Review learning model are as follows:

1. Determine the theme of learning

2. Determine the topic or theme focus for the implementation of the Plan Do Review learning model.

3. Prepare a scenario for implementing the Plan Do Review learning model.

4. Give an explanation to the child how to apply the Plan Do Review routine.

5. The teacher conveys the kinds of activities that will be carried out during the learning activities.

6. Teachers provide opportunities for children to get around to see what activity centers will be carried out.

7. Teachers provide opportunities for children to plan activities (Plan).

8. Children start their activities according to their planned (do).

9. After finishing, the child cleans the equipment he has used and then rests.

10. After finishing the break, the child reviews all the activities he has done (review).

In this study, the activity centers provided by the teacher were adjusted to the theme of learning that took place in kindergarten. The activities provided are also the result of discussions between teachers and children so that children play an active role in making daily activity plans by providing activity ideas. The duration of the Plan Do Review activity starts from the time the child enters the class until the child comes home which is 120 minutes. Besides this treatment can be done for approximately 3-4 times the treatment in a row.

(Brewer, 2007:386) defines that science is how children build curiosity by asking questions, investigating, and getting answers and dividing answers to other friends, which is done through observation, classification, drawing conclusions, and communicating.

According to (Rosalind Karen, 1995:54) reveals that science is the ability of children to obtain new information through concrete experiences carried out through observation, classification, measuring and communicating. According to (Nugraha, 2007: 5) states that science is a way to obtain knowledge. How to obtain knowledge through observation, experiments, finding concepts and formulating various theories. Cognitive development theory classifies children aged 2-7 years at the preoperational stage. Child's scientific ability at the preoperational stage is the ability to observe concrete objects by using all senses and then replacing using language, writing, or images as a place to attach meaning.

Observation activities are driven by children's curiosity about the surrounding environment so that they can observe the changes that occur. Then the child compares, estimates, classifies and communicates the results of observations as knowledge. In line with the previous opinion, (Nugraha, 2008) states that early childhood scientific ability is the ability to master science as a process, product, and attitude. Science ability as a process and product can be the ability to observe and carry out simple experiments. While the ability of science as an attitude can overcome various obstacles by actualizing science in his life.

The purpose of science learning according to (Nugraha, 2008: 35) is as follows:

1. Helping children understand scientific concepts and their relevance to everyday life.

2. Developing knowledge and ideas about the environment in children by attaching aspects related to science process skills.

3. Growing the interest of children to get to know and learn objects and events in their environment. 
4. Become a facilitator in developing an attitude of curiosity, diligence, openness, critical, introspective and responsible, working together and independently.

5. Helping children to apply scientific concepts in order to explain the symptoms of nature and solve problems in daily life.

6. Helping children to use simple technology that can be used to solve problems in everyday life.

7. Introduce and foster a love for the environment in children, so that they realize the greatness and majesty of God

\section{Research Methods:-}

The type of research used in this study is quasi-experimental design. The use of this type of research is based on the nature of the population, namely students who are not fixed and varied. This study examines two variables, namely the Plan Do Review learning model as an independent variable or influencing and the ability of science as a dependent variable or influenced.

There are two variables used in this study, namely the independent variable and the dependent variable. The independent variable or the one that influences is the influence of Plan Do Review learning methods, and the dependent or influenced variable is science learning in early childhood.

The research design used was nonequivalent control group design where measurements were carried out involving two groups, namely the experimental group and the control group. The research design can be described as follows (Sugiyono, 2013):

\begin{tabular}{|lll|}
\hline $\mathrm{O}_{1}$ & $\mathrm{X}$ & $\mathrm{O}_{2}$ \\
$\mathrm{O}_{3}$ & & $\mathrm{O}_{4}$ \\
\hline
\end{tabular}

\section{Information:}

Figure 1: Research Design

1. O1: Science ability of the experimental group before applying the Plan Do Review learning model

2. O2: Science ability of the experimental group after applying the Plan Do Review learning model

3. X: Treatment, namely the application of the Plan Do Review learning model

4. O3: Science ability of the control group before the Plan Do Review learning model

5. O4: Science ability of children who are not treated is in the form of a Plan Do Review learning model

Operational definitions are restrictions that are used to avoid differences in interpretations of the variables under study, while equating perceptions of the variables under study. The operational definitions of variables are as follows:

1. Plan Do Review learning model is a learning model with the principle of active learning and giving freedom to children by involving directly in the learning process and providing experience with people around them so that the learning environment must be able to support children's learning activities and can help children develop skills cognitive.

2. science ability is the child's curiosity to obtain new information that is done through observation, classification, drawing conclusions, and communicating

\section{Research Results and Discussion: -}

From the science ability test, the data obtained from science skills according to those given in this study consisted of data on scientific abilities of groups of children who followed the plan do review learning model and data on the ability of groups of children who followed conventional learning. Furthermore, the data obtained is calculated as mean, median, mode, standard deviation, variance, maximum score, minimum score, range and number of scores (sum). The score for the scientific abilities of the two data groups is 0-20.

\section{Description of Pretest Data.}

After the research was carried out, the data analysis results were presented in the form of pretest data decryption which was the result of the science ability test of the experimental and control group before being applied to the learning plan do review learning model as follows: 
Table 1:-Calculation Results of Descriptive Statistics of Pretest Data

\begin{tabular}{|c|c|c|}
\hline Statistic & Experimental Group Test Results & Control Group Test Results \\
\hline $\mathrm{N}$ & 10 & 10 \\
\hline Mean & 16 & 13,8 \\
\hline Median & 16,5 & 14 \\
\hline Modus & 18 & 14 \\
\hline STD V & 2,16 & 1,75 \\
\hline Variance & 2,20 & 1,20 \\
\hline Min score & 12 & 12 \\
\hline Max score & 18 & 18 \\
\hline Range & 6 & 6 \\
\hline Sum & 160 & 138 \\
\hline
\end{tabular}

Data description of pretest science ability group of children which follow the plan do review learning model. The scientific ability of groups of children who follow the plan do review learning model has a maximum score of 18 and a minimum score of 12 , with an average of 16, variants 2,200 and standard deviations 2,16.

Table 2:-Frequency Distribution of Science Capability Pretest Scores of Experimental Groups with Plan Do Review Learning Models

\begin{tabular}{|c|c|c|}
\hline Interval & Absolut Frequency (f) & Relative Frequency (\%) \\
\hline $12-13$ & 1 & 10 \\
\hline $14-15$ & 3 & 30 \\
\hline $16-17$ & 2 & 10 \\
\hline $18-19$ & 4 & 40 \\
\hline sum & 10 & 100 \\
\hline
\end{tabular}

The table shows the scientific abilities of children who follow the plan do review learning model at 12-13 intervals, there are 1 respondent with a percentage of $10 \%$, intervals 14-15 there are 3 respondents with a percentage of $30 \%$, interval 16-17 there are 2 respondents with a percentage of $20 \%$, and the $18-19$ intervals have 4 respondents with a percentage of $40 \%$.

To be clearer, the data can be presented in the form of the following histogram:

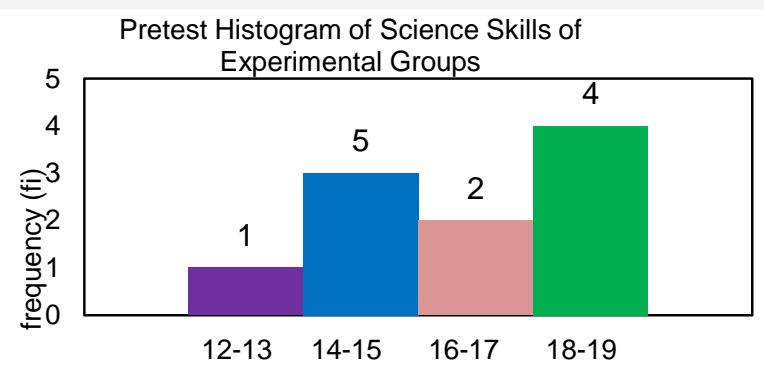

Figure 2: -Histogram Scores of Science's Pretest Ability in Experimental Groups with Plan Do Review Learning Models

Based on the histogram, it can be known the categories of each interval. The 18-19 interval has 4 respondents who are included in the high category, the interval 16-17 there are 2 respondents who belong to the high category, the interval 14-15 there are 3 respondents who are in the moderate category, while the 12-13 interval there is 1 respondent who is in the low category. With these categorization, there are 6 respondents who are included in the high category and 3 respondents are included in the medium category and 1 respondent is in the low category.

Data description of pretest science ability group of children who will take conventional learning.

Science skills of groups who will take conventional learning have a maximum score of 18 and a minimum score of 12 with an average of 13.8, variant 1.20 and standard deviation 1.75. 
Table 3: -Frequency Distribution Pretest Scores of Science Capability of Conventional Groups.

\begin{tabular}{|c|c|c|}
\hline Interval & Absolut Frequency (f) & Relative Frequency (\%) \\
\hline $12-13$ & 3 & 600 \\
\hline $14-15$ & 6 & 0 \\
\hline $16-17$ & 0 & 10 \\
\hline $18-19$ & 1 & 100 \\
\hline sum & 10 & 0 \\
\hline
\end{tabular}

The table shows the children's scientific abilities that follow conventional learning at 12-13 intervals, there are 3 respondents with a percentage of 10\%, 14-15 intervals there are 6 respondents with a percentage of $40 \%$, interval 16-17 there are 0 respondents with a percentage of $0 \%$, and intervals 18-19 there is 1 respondent with a percentage of $40 \%$.

To be clearer, the data can be presented in the form of the following histogram:

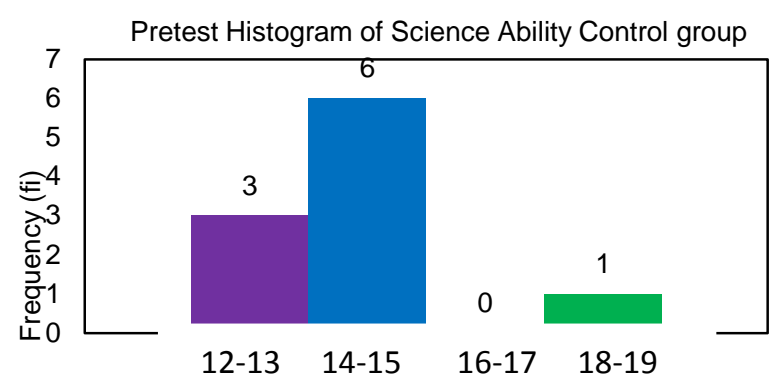

Figure 3: -Histogram Pretest Score in Science Capability of Conventional Groups

Based on the histogram, it can be known the categories of each interval. The 18-19 interval has 1 respondent who belongs to the high category, interval 16-17, there are 0 respondents who belong to the high category, the interval 14-15 there are 6 respondents who are in the moderate category, while the 12-13 interval there are 3 respondents who are in the low category. With these categorization, there are 1 respondent who is included in the high category and 6 respondents who are in the moderate category and 3 respondents who are in the low category.

\section{Description of Posttest Data}

After the plan do review learning model was applied in the experimental group, the posttest data from the results of the science ability test of the experimental group and controls were presented to compare with the pretest data obtained before the application of learning and learning methods.

Table 4.:-Calculation Results of Posttest Data Descriptive Statistics

\begin{tabular}{|l|l|l|}
\hline Statistic & Experimental Group Test Results & Control Group Test Results \\
\hline $\mathrm{N}$ & 10 & 10 \\
\hline Mean & 18 & 16 \\
\hline Median & 18,5 & 15,5 \\
\hline Modus & 20 & 14 \\
\hline STD V & 2,11 & 2,00 \\
\hline Variance & 2,30 & 0,30 \\
\hline Min score & 14 & 14 \\
\hline Max score & 20 & 20 \\
\hline Range & 6 & 6 \\
\hline Sum & 180 & 160 \\
\hline
\end{tabular}

Data description of posttest science ability group who follow the plan do review learning model.

Science ability groups of children who follow plan do review have a maximum score of 20 and a minimum score of 14 , with an average of 18 , variants of 3.30 and standard deviation of 2.11 
Table 5:-Frequency Distribution of Posttest Scores of Science Capabilities Experimental Groups with Plan Do Review Learning Models

\begin{tabular}{|c|c|c|}
\hline Interval & Absolut Frequency (f) & Relative Frequency (\%) \\
\hline $14-15$ & 2 & 20 \\
\hline $16-17$ & 1 & 10 \\
\hline $18-19$ & 4 & 40 \\
\hline $20-21$ & 3 & 30 \\
\hline sum & 10 & 100 \\
\hline
\end{tabular}

The table shows the scientific abilities of children who follow the plan do review learning model at 14-15 intervals, there are 2 respondents with a percentage of 20\%, intervals 16-17 there are 1 respondent with a percentage of $10 \%$, intervals of 18-19 there are 4 respondents with $40 \%$, and interval 20-21 there are 3 respondents with a percentage of $30 \%$.

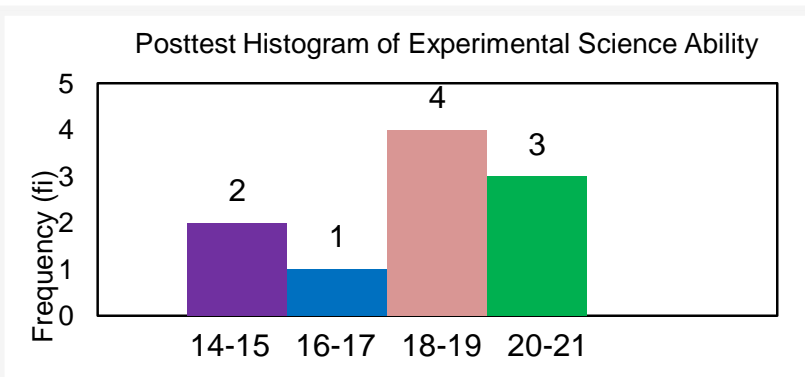

Figure 4:-Histogram Score Posttest Science Ability Experimental Groups with Plan Do Review Learning Models

Based on the histogram, it can be known the categories of each interval. The 20-21 interval has 3 respondents who are included in the high category, the interval 18-19 there are 4 respondents who belong to the high category, the interval 16-17 there is 1 respondent who is in the moderate category, while the interval 14-15 there are 2 respondents who are in the low category. With these categorization, there are 7 respondents who are included in the high category and 1 respondent is included in the medium category and 2 respondents are in the low category.

\section{Description of science capability data for groups in conventional learning}

Science skills of groups of children who take conventional learning have a maximum score of 20 and a minimum score of 14 , with an average of 16 variants of 0.30 and standard deviation of 2.00 .

Table 6:-Frequency Distribution of Posttest Scores in Scientific Capabilities of Conventional Groups

\begin{tabular}{|c|c|c|}
\hline Interval & Absolut Frequency (f) & Relative Frequency (\%) \\
\hline $14-15$ & 5 & 50 \\
\hline $16-17$ & 3 & 30 \\
\hline $18-19$ & 1 & 10 \\
\hline $20-21$ & 1 & 10 \\
\hline Sum & 10 & 100 \\
\hline
\end{tabular}

The table shows the ability of children to take part in learning through constructive play using natural media at intervals of 14-15, there are 5 respondents with a percentage of 50\%, interval 16-17, there are 3 respondents with a percentage of $30 \%$.

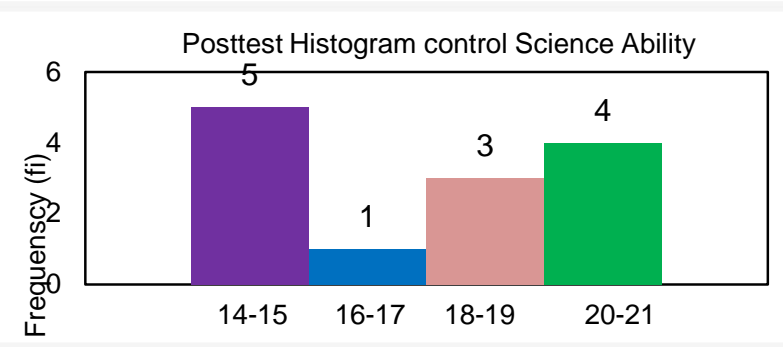

Figure 5:-Histogram Posttest Score Conventional Science Capability 
Based on the histogram, it can be known the categories of each interval. The 20-21 interval has 1 respondent in the high category, the interval 18-19 there is 1 respondent who belongs to the high category, the interval 16-17 there are 3 respondents who are in the moderate category, while the interval 14-15 there are 5 respondents who are in the low category. With these categorization, there are 2 respondents who are included in the high category and 3 respondents are included in the medium category and 5 respondents are included in the low category.

\section{Testing Requirements for Analysis}

The normality test is carried out to find out whether the study sample comes from a population that is normally distributed. While the homogeneity test is conducted to find out whether the research data that has been collected comes from a homogeneous population.

\section{Normality test}

The normality test in this study used the Liliefors normality test conducted on two groups of data, namely the ability of scientific creativity in the group of children who followed the plan do review learning model and the ability of science groups of children who followed conventional learning. The summary of the calculation results for the normality test of the two research groups is presented in the following table:

Table 7:-Summary of the Normality Test of Science Ability Score Data

\begin{tabular}{|l|c|c|c|c|}
\hline Data group & $\mathrm{N}$ & $\left(L_{h}\right)$ & $L_{t}(\alpha=0,05)$ & Info \\
\hline Experiment & 10 & 0,20 & 0,26 & normal \\
\hline control & 10 & 0,16 & 0,26 & normal \\
\hline
\end{tabular}

The table shows that L_count ( $\mathrm{Lh})$ in the experimental group and conventional groups are smaller than L_tabel (Lt), so it can be concluded that the study sample came from populations that were normally distributed.

\section{Homogeneity Test}

The homogeneity test in the two groups was carried out through the F test which is calculating the F-ratio between the largest variants and the smallest variant of the group tested, then compared with price $\mathrm{F}$ table $(\mathrm{Ft})$ the 0.05 significance level.

Based on the calculation results as in the appendix, the results of $F_{-}$(count) and $F_{-}$(table) are obtained so that it can be concluded that the scores of scientific abilities of the two groups come from populations that have a homogeneous variance. Thus inferential statistical tests (t-test) can be continued to test hypotheses.

\section{Hypothesis testing}

The results of calculations using the hypothesis-t test were conducted on two groups which became the study sample where the data tested was a score of science ability. Based on the results of the t-test calculation (Separated Variant) as found in the attachment, it is obtained t_count $=2.178$ with the price t_(table $=) 1.734$ and $\mathrm{dk}=18$ and the significance level $\alpha=0.05$. So that when compared to price t_count $=2.178>\mathrm{t}$ _ $($ table $=) 1.734$. This data shows a significant difference between the two groups tested. This shows that H1 is accepted, meaning that there is influence of the plan do learning model on children's scientific abilities.

\section{Conclusion:-}

Learning with the plan do review learning model is more effective than conventional learning.

Based on the results of the t-test calculations, there was a significant difference between the ability of the science group of children who followed the plan do review learning model and the group of children who followed conventional learning. In this case, the average score of children's creativity ability for groups of children who follow the plan do review learning model is higher compared to the average score of science ability scores for groups of children who follow learning with conventional activities.

This is because science playing activities using the plan do learning model invites children to be more creative, active, more focused, the cohesiveness between one child and another child, invites children to empathize, communicate, work together, understand others and creating a more exciting and fun class atmosphere.

(Morrison, 2008) revealed that the Plan Do Review program was based on Piaget's theory, Constructivism, Dewey, and Vygotsky. The point is that the Plan Do Review model is a child-centered learning approach and prioritizes 
children actively involved in both planning and learning. Learning activities are designed according to the interests of children so that the determination of learning activities by teachers and children is carried out in a balanced manner. Plan Do Review is a cycle of teaching and learning. Plan Do Review is one of the child-centered learning approaches. In this approach, children are given the opportunity to carry out learning activities according to their interests and desires, starting from making a plan, at this stage the teacher gives the opportunity to the child to plan their activities with the help of the teacher's direction, then (Do) plan in groups, and the last is (Review), the child reports back/reviewing what he has done.

(Nugraha, 2008) states that early childhood scientific ability is the ability to master science as a process, product, and attitude. Science ability as a process and product can be the ability to observe and carry out simple experiments. While the ability of science as an attitude can overcome various obstacles by actualizing science in his life.

In this study, the activities provided are explained in the learning scenarios that have been made. These activities, among others, the teacher first prepares the tools and materials to be carried out, then the teacher explains the activities of playing science to students. After that, science playing activities are carried out, including:

1. Children can know the scales

2. Children can know the concept of floating objects

3. Children are able to do simple experiments

4. Children know animals that live on land

5. Children can get to know the types of vegetable plants

The role of the teacher as an educator in this activity is to direct students to play science, such as when children are introduced to the scales, do simple experiments, etc. Thus the child will feel very impressive and happy with what the child does himself in playing science. every activity carried out, students are very excited and often feel curious about every activity that will be carried out, the child will guess and ask repeatedly about the game tool for what other activities will be made and always want to repeat it again. In addition to developing cognitive abilities, this activity also increases children's knowledge and curiosity which is very helpful in developing every potential in themselves to develop aspects of a child's development in both the motoric, language, religious and moral and social emotional aspects.

The explanation above further supports that science activities with a plan do review learning model are very effective for improving early childhood science skills compared to conventional learning. In science playing activities with conventional learning the teacher uses activities by only giving explanations and using existing images, thus learning is only centered on the teacher and the child does not feel directly playing the science.

The opposite applies when using the plan do review learning model when playing science, the child is not only silent and sitting listening to the explanation from the teacher to work on the activity, but the child is more active in exercising his creative ability to solve scientific games performed and during playing activities child science can be satisfied with what has been produced from his own hands, it can be useful for one of the direct experiences for children in the future.

Based on the explanation above, it can be said that the plan do review learning model of children's scientific abilities is very influential is one of the good stimulations for developing children's scientific abilities. Thus it can be seen that there are a number of things that cause differences in children's science ability scores between groups who take part in the learning with the plan do review learning model with conventional learning methods, in which the child's scientific ability score following the learning plan do review model is 18,00 from the group of children who take conventional learning, namely 16,00 .

\section{Conclusion:-}

Based on the results of the analysis and statistical tests in the previous discussion, it can be concluded that:

1. The results of the scientific ability for the group of children with the plan do review learning model are high.

2. The results of children's scientific abilities for groups of children who follow conventional learning are in the moderate category.

3. There is an effective influence when applying the plan do learning model to children's scientific ability. 


\section{References:-}

1. Ardi Wiyani, Novan. (2014). Psychology of Early Childhood Development. Yogyakarta: Gava Media.

2. Arikunto, Suharsimi. (2010). Research Procedure A Practice Approach. Jakarta: Rineka Cipta.

3. Brewer, Jo Ann. (2007). Introduction to Early Childhood Education. Boston: Pearson Education, Inc.

4. Papalia, D. E, Old s, S. W., and Feldman, R. D. (2009). Human Development of Human Development. Jakarta: Salemba Humanika.

5. Karen, Rosalind. (1995). Math and Science for young Children, New York: Delmar Publishing.

6. Ministry of Education and Culture. (2015). 2013 Curriculum for Early Childhood Education. Regulation of the Minister of Education and Culture of the Republic of Indonesia Number 137 of 2014.. Jakarta.

7. Ministry of Education and Culture. (2015. 2013 Curriculum for Early Childhood Education. Regulation of the Minister of Education and Culture of the Republic of Indonesia Number 146 of 2014. Jakarta.

8. Morrison, G. (2008). Basics of Early Childhood Education. Jakarta: Index

9. Nugraha, Ali. 2008. Development of Science Learning in Early Childhood. Bandung: Jilsi Foundation.

10. Nugraha, Ali. (2007). Development of Science Learning in Early Childhood. Bandung,

11. Rahmawati, Yeni and Kurnati, Euis. (2010). Strategy for Developing Creativity in Kindergarten Children. Jakarta: Kencana

12. Roopnarine, Jaipaul L \& Johnson, James E. (2011), Early Childhood Education in Various Approaches, Jakarta: Kencana Prenada Media Group.

13. Sanjaya, W. (2007). Learning Strategies, Oriented Education Process Standards. Jakarta: Kencana Prenada Media Group

14. Santrock, John W (2007). Child development. Jakarta: Erlangga

15. Sugiyono. (2016). Quantitative, Qualitative, and R \& D Research Methods. Bandung: Alfabeta.

16. . (2013). Educational Research Methods. Bandung: Alfabeta.

17. Susanto, Ahmad. (2011). Early Childhood Development. Jakarta: Kencana.

18. Suyanto, Slamet. (2012). Introduction to Science for Kindergarten Children with an "Open Inquiry" Approach. Site Staff of Yogyakarta State University. (online) .http: //staff.uny.ac.id/sites/default/files/131930139/journal\%20PENGENALAN\%20SAINS\%20UNTUK\%20ANAK \%20TK.pdf. (accessed 06 April 2018).

19. Suyanto. (2008). Child Education Strategy. Yogyakarta: Hikayat

20. Law of the Republic of Indonesia Number 20 of 2003 concerning the National Education System.

21. Wiyani, Novan Ardy \& Barnawi. (2012). PAUD Format Concept, Characteristics \& Implementation of Early Childhood Education. Jogjakarta: Ar-Ruzz Media

22. Yus, Aanita. (2011). Early Childhood Education Model. Jakarta: Kencana

23. Yulianti, Dwi. (2010). Playing While Learning Science in Kindergarten. Jakarta: PT. Index. 